\title{
Hormone-mediated repression: a negative glucocorticoid response element from the bovine prolactin gene
}

\author{
Dennis D. Sakai, ${ }^{1,4}$ Sherron Helms, ${ }^{2}$ Jan Carlstedt-Duke, ${ }^{3}$ Jan-Åke Gustafsson, ${ }^{3}$ Fritz M. Rottman, ${ }^{2}$ \\ and Keith R. Yamamoto ${ }^{1}$ \\ ${ }^{1}$ Department of Biochemistry and Biophysics, University of California, San Francisco, San Francisco, California 94143-0448 \\ USA; ${ }^{2}$ Department of Molecular Biology and Microbiology, Case Western Reserve University School of Medicine, Cleveland, \\ Ohio 44106 USA; $^{3}$ Department of Medical Nutrition, Karolinska Institutet, Huddinge Hospital F69, S-14186 Huddinge, Sweden
}

\begin{abstract}
We have defined and characterized a region upstream of the bovine prolactin gene that confers repression by glucocorticoids. This 'negative glucocorticoid response element' (nGRE) contains multiple footprinting sites for purified glucocorticoid receptor protein between -51 and $-562 \mathrm{bp}$. A strong consensus sequence for receptor binding within the nGRE has not yet been defined, but it is apparent that nGRE sequences differ from the GRE consensus elements that confer positive glucocorticoid regulation. Unlike 'positive' GREs, the nGRE enhances promoter activity in the absence of glucocorticoids or receptor, presumably through the action of a protein that binds in the same region and activates transcription. The hormone-receptor complex appears to negate this enhancement by competing or inactivating the second factor. As with positive GREs, nGRE sequences confer hormonal regulation upon linked heterologous promoters within various cell types; a 34-bp subfragment containing a single receptor binding site is sufficient for nGRE activity. We speculate that $\mathrm{nGRE}$ sequences might alter the structure of bound receptor, thereby preventing it from functioning as a positive regulator when bound at those sites.
\end{abstract}

[Key Words: Glucocorticoid receptor; prolactin gene; repression]

Received April 11, 1988; revised version accepted July 13, 1988.

The glucocorticoid receptor protein transduces the signaling information of hormonal ligands into specific changes in gene expression: upon hormone binding, the receptor-hormone complex undergoes nuclear localization (Picard and Yamamoto 1987), associates with genomic sites, and alters the efficiency of transcriptional initiation at specific promoters (for review, see Yamamoto 1985). As with other transcriptional regulatory factors (Borrelli et al. 1986; Bram et al. 1986; Johnston 1986; Ptashne 1986), the glucocorticoid receptor stimulates transcription from some promoters while downregulating others. Its positive regulatory effects are conferred by binding to a specific class of transcriptional enchaners termed glucocorticoid response elements (GREs) (Chandler et al. 1983; Ponta et al. 1985; DeFranco and Yamamoto 1986; Miksicek et al. 1986). Mutational analyses of a mouse mammary tumor virus (MTV) GRE suggested that the receptor is the only specific binding factor required for GRE enhancer activity (DeFranco et al. 1985; Buetti and Kühnel 1986). The GRE-bound receptor presumably interacts with some component of the transcription initiation apparatus, thereby stimulating its activity (Yamamoto 1985). GREs that mediate positive regulatory effects have now been shown to reside within or near a variety of genes (e.g., Karin et al. 1984; Renkawitz et al. 1984; Moore et al.

Present address: Department of Biological Sciences, University of Southern California, Los Angeles, California 90089-1481 USA.
1985; Danesche et al. 1987; Jantzen et al. 1987), and a common consensus sequence, similar to that identified within MTV GREs (Payvar et al. 1983; Scheidereit et al. 1983), has been identified.

Negative regulation of transcription by glucocorticoids has been clearly documented (Camper et al. 1985; Israel and Cohen 1985; Charron and Drouin 1986; Fremeau et al. 1986; Frisch and Ruley 1987; Weiner et al. 1987), but the role of specific receptor-DNA interactions and the mechanistic relationships of positive and negative control have not been defined. In this report, we identify sequences upstream of the bovine prolactin gene that confer negative glucocorticoid regulation upon the prolactin promoter in anterior pituitary cells (Camper et al. 1985). In particular, we describe properties of a 'negative GRE' (nGRE) in this region, test glucocorticoid receptor binding to the nGRE, and examine nGRE activity in heterologous cells and on heterologous promoters.

\section{Results}

Glucocorticoid receptor binding sites upstream of the bovine prolactin gene

Camper et al. (1985) showed that the bovine prolactin promoter and $1 \mathrm{~kb}$ of $5^{\prime}$ flanking DNA are sufficient to mediate glucocorticoid-repressible expression of a linked chloramphenicol acetyltransferase (CAT) gene in 
transfected GH3 rat pituitary cells. To determine whether the receptor binds selectively within that region, we carried out DNase I footprinting assays with glucocorticoid receptor purified from rat liver (Payvar et al. 1983; Wrange et al. 1986). Seven footprints were detected between -50 and -562 relative to the transcription start site. Receptor protected both strands of DNA and displayed different binding efficiencies at the different sites (Fig. 1); for example, footprint 7 is $>10$-fold stronger than the relatively weak footprint 3 . In general, the range of apparent affinities was similar to that observed on MTV DNA with similar receptor preparations (data not shown; Payvar et al. 1983). The DNA sequences within the footprints lack extensive similarity, although each includes sequences that are weakly related to the octanucleotide consensus element $\left(\mathrm{AGA}^{\mathbf{A}_{\mathrm{T}}} \mathrm{CAG} \mathrm{A}^{\mathbf{A}_{\mathrm{T}}}\right)$ implicated in receptor binding and enhancer activity at 'positive' GREs (Fig. 2). Whether these consensus-like sequences are in fact determinants of specific receptor binding within the prolactin upstream region is unknown; in any case, the putative nGRE se- quences do not adhere as closely to the consensus as those associated with positive GRE function.

Although the receptor is encoded by a single-copy gene (Miesfeld et al. 1984), functionally distinct forms could arise in principle post-transcriptionally. Different receptor isoforms might then recognize different classes of DNA sequences and mediate either negative or positive transcriptional regulation. To test this possibility, we performed competition footprinting experiments in which the labeled DNA fragment contained high-affinity receptor binding sites derived from an MTV GRE (Payvar et al. 1983) cloned adjacent to the prolactin footprint 3 region (PRL3; -247 to -214 ) described above (Fig. 3; see also Fig. 6). As shown in Figure 3, footprinting on PRL3 required approximately 10-fold more receptor than that needed for a similar level of occupancy at the MTV-derived binding sites (MTV46). Nevertheless, both the prolactin and MTV46 footprints were competed by excess unlabeled DNA from either the weak PRL3 or the strong MTV46 binding sequences, whereas a control prolactin fragment $(-230$ to -188$)$

The Prolactin $5^{\prime}$ Flanking Region Contains Multiple Binding Sites for Glucocorticoid Receptor

A

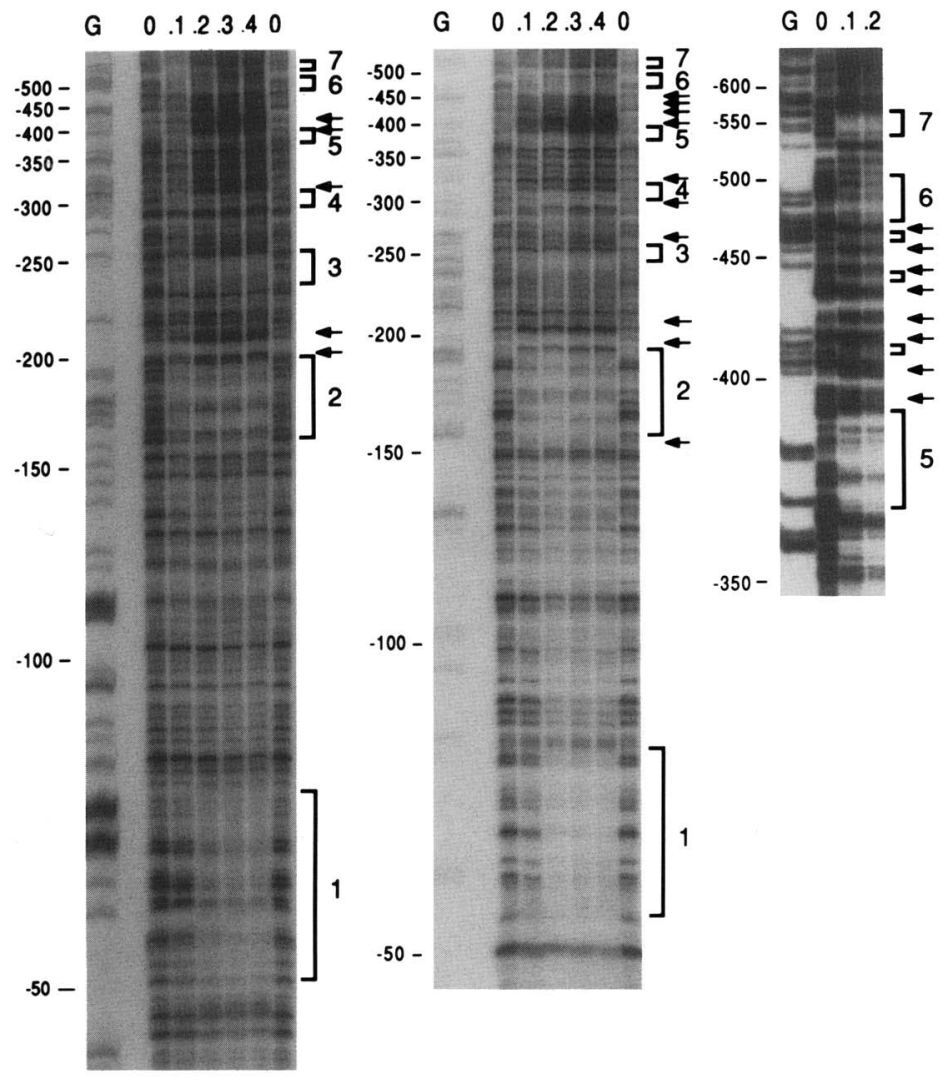

Figure 1. DNase I footprint analysis of glucocorticoid receptor binding to prolactin DNA. Prolactin DNA was $(A) 3^{\prime}$-end-labeled or $(B) 5^{\prime}$-end-labeled at a BamHI site $(+22)$ or (C) $5^{\prime}$-end-labeled at a BgIII site $(-248)$ and footprinted with $0-0.4 \mu \mathrm{g}$ purified glucocorticoid receptor as indicated. (Lane G) Probe DNA submitted to guanosine-specific cleavage. Sequences protected from DNase digestion are indicated by brackets; sites of enhanced cleavage are marked with arrows. Diagram shows positions of these features relative to the prolactin transcription initiation site. 


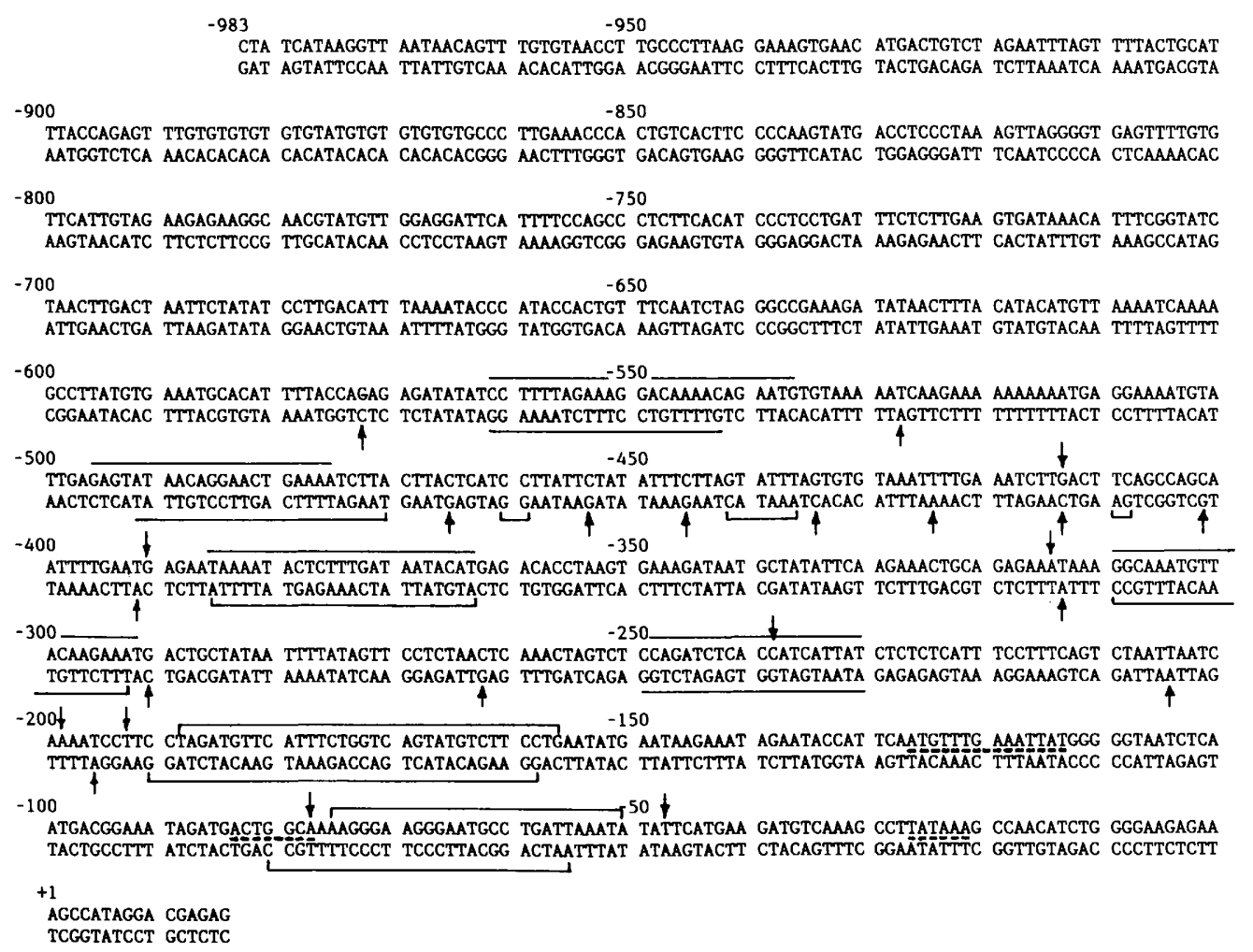

Figure 2. DNA sequences of the bovine prolactin $5^{\prime}$-flanking region bound by glucocorticoid receptor and location of receptor binding sites. The nucleotide sequence of bovine prolactin DNA from plasmid pPRLcat-1 (Camper et al. 1984, 1985) is presented. Receptor footprints are demarcated by lines above and below the DNA sequence for the coding and noncoding strands, respectively. Sites hypersensitive to cleavage in the presence of receptor are indicated by arrows. Dashed lines indicate putative TATA box and CCAAT box sequences at -25 and -80 , respectively, and a sequence at -120 that has been observed in all members of the growth hormone gene family (Rottman et al. 1986).

not recognized by receptor failed to compete. Thus, the relative affinities of receptor binding in vitro to these MTV-derived and prolactin sequences are within approximately one order of magnitude, and receptor binding near positively and negatively regulated genes apparently is accomplished by a common pool of receptor rather than by distinct, noncompeting forms.

\section{Effects of the receptor binding region on prolactin promoter activity}

To assess whether the DNA segment bound specifically by glucocorticoid receptor in vitro might modulate prolactin promoter activity in vivo, we constructed a series of nested $5^{\prime}$ deletion mutants that progressively truncated the flanking DNA upstream of the prolactin promoter, which was fused at +16 to the CAT coding region. Plasmids carrying these constructs were transfected into GH3 cells, and CAT activities measured in transient expression assays (Gorman et al. 1982). In addition, accurately initiated prolactin-CAT mRNA was monitored by RNase mapping (Melton et al. 1984), and relative transcript levels were calculated by normalization to an internal control mRNA expressed from a cotransfected plasmid bearing a Rous sarcoma virus pro-
moter-CAT gene fusion, which is not glucocorticoid regulated (see Fig. 4).

Consistent with previous results (Camper et al. 1985), we found that dexamethasone treatment reduces by three- to four-fold the level of prolactin-CAT transcripts produced by constructs containing at least $310 \mathrm{bp}$ of $5^{\prime}$ flanking sequence (see Fig. 4). Further deletion, however, resulted in a progressive decline in both basal (i.e., 'unrepressed' or glucocorticoid independent) expression and in the extent of repression. Deletions to positions -290 to -236 , which remove footprint 4 but not footprint 3 , are repressed 2- to 2.5 -fold by hormone treatment. Low levels of hormone regulation were observed with deletion mutants containing between 229 and $173 \mathrm{bp}$ of flanking sequence, which retains only footprints 1 and 2; deletion to -45 abolished detectable transcription. Thus, we conclude that sequences encompassing footprints $1-4$ yield hormonal regulation that is indistinguishable from that seen when all seven receptor footprints are present (Fig. 4). The decreased repression observed with deletion mutants containing less than 310 bp of 5 ' flanking DNA suggests that sequences within or near footprint sites 2,3 , and 4 contribute to optimal hormonal regulation; footprint 1 alone/deletions -152 to -78 ) fails to confer significant glucocorticoid regulation in this context. 


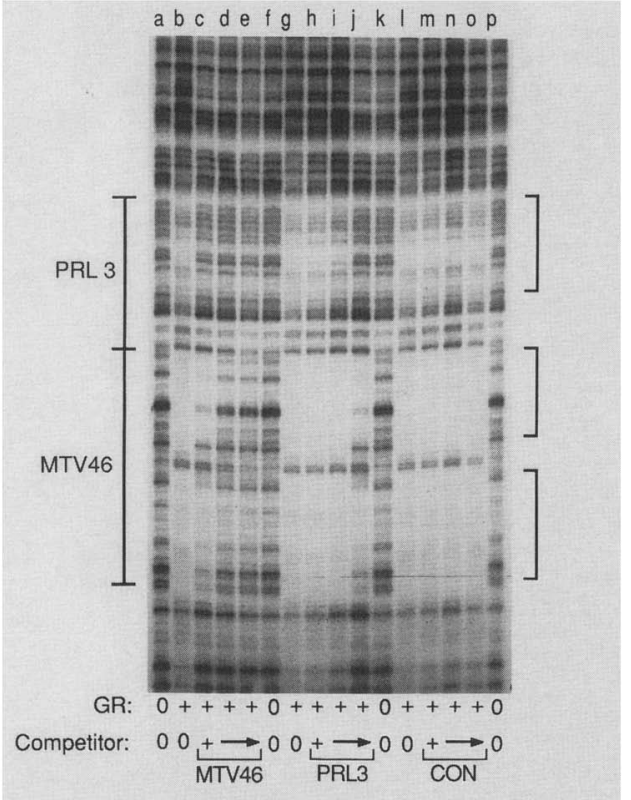

Figure 3. GRE and nGRE competition footprinting analysis of glucocorticoid receptor binding to prolactin and MTV sequences. A 650-bp fragment from plasmid MTV-152 (see Fig. 6) was $3^{\prime}$-end-labeled at a HindIII site $(+18)$ and footprinted with $100 \mathrm{ng}$ of rat liver glucocorticoid receptor in the absence or presence of competitor DNAs. Brackets indicate positions of receptor footprints within the PRL3 and MTV46 segments of the fragment. Competitor DNAs: (lanes $c-e$ ), a 58-bp XbaI fragment containing two copies of MTV nucleotides -123 to -105 (MTV46); (lanes $h-i)$ 49-bp XbaI fragment containing prolactin nucleotides -247 to -214 (PRL3); (lanes $m-0$ ) 57-bp XbaI fragment containing a nonfootprinted prolactin region, nucleotides -230 to -188 (CON). Reactions contained 2.3 fmoles of ${ }^{32} \mathrm{P}$-labeled DNA together with 0 (lanes $\left.a, b, f, g, k, 1, p\right), 0.23$ (lanes $c, h, m$ ), 0.7 (lanes $d, i, n$ ), or 2.3 (lanes $e, j, o$ ) pmoles of competitor DNA; reactions in lanes $a, f, k$, and $p$ lacked receptor.

The gradual loss of glucocorticoid-mediated repression observed with progressive $5^{\prime}$ deletion reflects predominantly a decrease in promoter activity observed in the absence of hormone, whereas the absolute level of transcription in the presence of dexamethasone remains, in general, relatively constant (Fig. 4). This implies that the prolactin $5^{\prime}$-flanking sequences comprise a complex regulatory region containing contiguous or interdigitated elements responsible both for conferring glucocorticoid responsiveness and for establishing a high level of promoter activity in the absence of glucocorticoids.

To characterize in greater detail the roles of receptor binding sites, 1, 2, and 3 in glucocorticoid-mediated repression, the three sites were mutated individually in constructs lacking footprint regions $4-7$. In this context, we found that alteration of any of the three remaining sites decreased both basal transcription from the prolactin promoter and eliminated glucocorticoid regulation. Thus, 5 ' deletion to -212 , which eliminates receptor footprint site 3 , reduced basal expression (by about four-fold in this experiment) relative to constructs extending to -248 , and greatly diminished hormonal regulation (Fig. $5 a$, b; see also Fig. 4). Interestingly, reinsertion of the PRL3 region $(-214$ to -247$)$ in the inverted orientation restored both basal transcription and hormone-mediated repression (Fig. 5c). This suggests that, as with the GREs that confer positive hormonal regulation, putative nGRE elements can function in both orientations. Linker substitution (LS) mutations that selectively disrupted footprints 2 or 1 were phenotypically similar to the footprint site 3 deletion. Thus, LS $-170 /-152$ and LS $-70 /-59$ interfere, with receptor footprinting at sites 2 and 1, respectively, in vitro (data not shown), and reduce basal expression and hormonal regulation in vivo (Fig. 5d,e). In contrast, a linker substitution mutation (LS $-214 /-202)$ that had no effect on receptor binding altered neither expression nor glucocorticoid responsiveness (Fig. 6 and data not shown).

Taken together, our results indicate that prolactin promoter activity is governed by a relatively large and complex region which, at the minimum, must include footprint regions 1,2 , and 3 .

\section{Linkage to an MTV GRE renders the prolactin promoter inducible by glucocorticoids}

It seemed conceivable that GRE and putative nGRE sequences, per se, might be functionally indistinguishable, but that the prolactin promoter, within the physiological context of anterior pituitary cells, might 'interpret' the bound receptor as a negative regulator. As an initial test, we inserted MTV46, a 46-bp synthetic oligonucleotide, whose sequence was derived from an MTV GRE, into various positions within the prolactin flanking sequence. Neither induction nor repression was observed when MTV46 was positioned upstream of receptor footprint site 3 (Fig. 6 c); this may indicate that the GRE and nGRE elements function with equal (i.e., offsetting) activity in this configuration. Consistent with this view, MTV46 strongly enhances, in a hormone-dependent fashion, other promoters into which it is similarly positioned (data not shown). With the GRE positioned between footprint sites 2 and 3, a three-fold induction by glucocorticoids was observed (Fig. 6d), and the induction increased to greater than 20-fold as the GRE was moved closer to the prolactin start site with concomitant deletion of footprint sites 2 or 1 (Fig. 6e,f). These results demonstrate a strong position dependence of GRE activity in the context of the prolactin promoter.

We conclude that the prolactin promoter does not, per se, respond negatively to the glucocorticoid receptor within pituitary cells. Rather, both positive and negative glucocorticoid regulation can be sensed by this promoter. Therefore, transcription factors or other components necessary for both modes of regulation must coexist within this cell type. Most importantly, these results suggest strongly that GRE and nGRE sequences themselves must somehow dictate whether a single regulatory protein, the glucocorticoid receptor, is to act as a positive or negative regulator. 
Sakai et al.

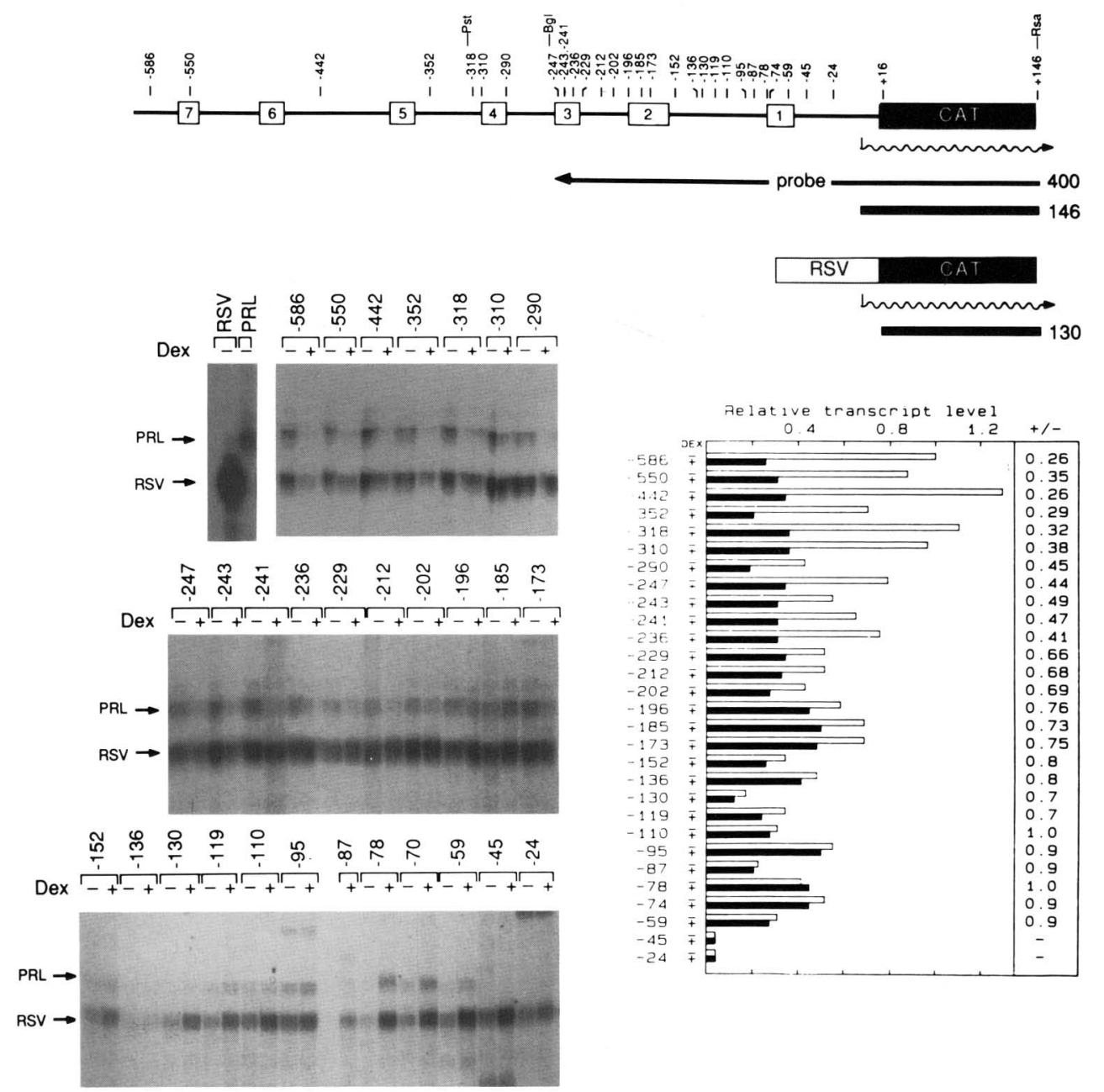

Figure 4. Expression and glucocorticoid regulation from prolactin gene $5^{\prime}$ deletion mutants. Test plasmids $(15 \mu \mathrm{g})$ bearing $5^{\prime}$-terminal deletions in the prolactin flanking region were cotransfected with a reference plasmid pRSVcat (1 $\mu \mathrm{g})$ into GH3 cells with ( + ) or without $\left(-\mid 0.1 \mu \mathrm{M}\right.$ dexamethasone. Poly $(\mathrm{A})^{+}$RNA was isolated $48 \mathrm{hr}$ later and the $5^{\prime}$ ends were analyzed by RNase protection. Autoradiographs representative of RNase protection assays are shown. The positions of probe fragments protected by accurately initiated transcripts from the test (PRL) and reference (RSV) genes are indicated; control transfections with $15 \mu \mathrm{g}$ of pPRLcat-2 $\left(5^{\prime} \Delta-248\right)$ or pRSVcat alone are shown in lanes RSV and PRL. The graph depicts densitometric quantitation of prolactin-CAT transcripts. All values are normalized to the reference signal and represent the mean expression level from two to six independent transfections; relative expression of $\leqq 0.05$ was indistinguishable from film background in these assays. Diagram shows positions of the seven receptor footprints relative to deletion end points; also indicated is the probe fragment and the species protected by accurately initiated prolactin-CAT transcripts (146 nucleotides) and RSV-CAT transcripts (130 nucleotides). Note the 5' $\Delta$-236 deletes most of footprint 3 sequence but does not abolish footprinting at that position (see text); this may reflect substantial similarity between the fused sequences (see Materials and methods) and the wild-type sequences (Fig. 2).

\section{$n G R E$ effects on a heterologous promoter in nonpituitary cells}

As a direct test of our interpretation that GRE and nGRE sequences are functionally distinct, we fused various subfragments of the prolactin flanking region to the herpes simplex virus thymidine kinase (tk) promoter, and examined basal promoter and hormone regulatory capacity of these constructs in transiently transfected nonpituitary cells. Similar results were obtained with several different recipient cell lines. Here we present data from the monkey kidney cell line CV-1, which lacks endogenous glucocorticoid receptor activity (Miesfeld et al. 1986). With this line, we could readily test the role of glucocorticoid receptor protein in nGRE function by assessing the requirement for cotransfected plasmids that express receptor coding sequences (see Materials and methods).

We found that a 34-bp prolactin subfragment containing receptor footprint region 3 (PRL3; -247 to -214 ) rendered the tk promoter glucocorticoid repressible in a receptor-dependent fashion when fused in either orientation upstream of the promoter (Fig. 7e-h) or (weakly) when situated downstream of the transcription 

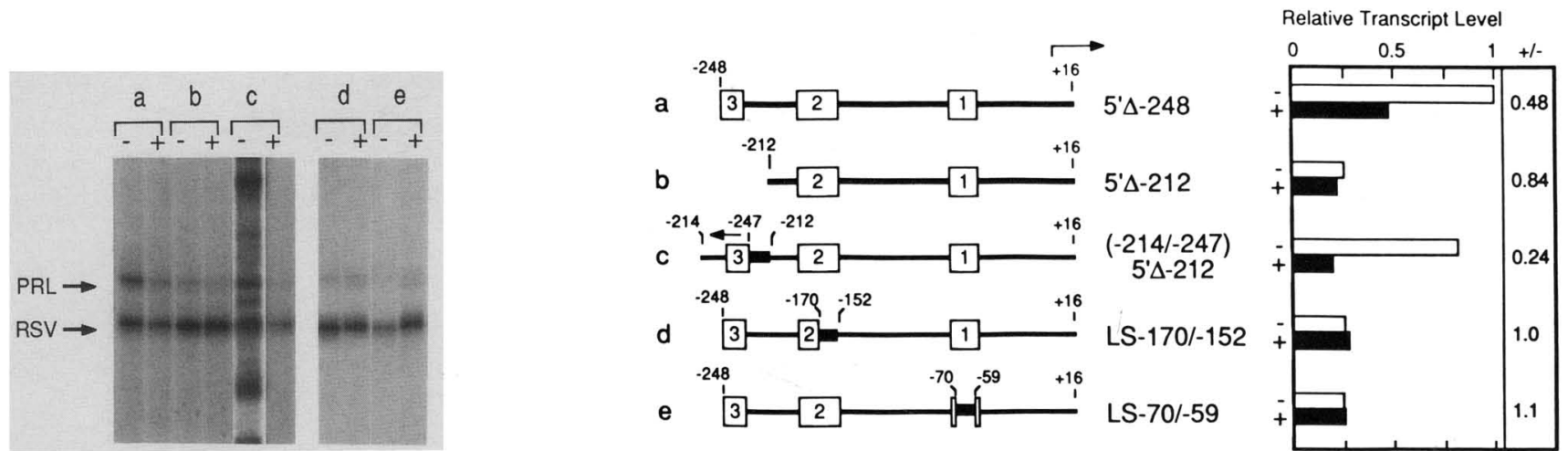

Figure 5. Expression and glucocorticoid regulation from linker substitution and inversion mutations of the prolactin regulatory region. Receptor binding sites 1,2, and 3 are required for glucocorticoid repression. Site 3 functions in an inverted orientation. Test (prolactin-CAT fusions) and reference (pRSVcat) plasmids were contransfected into GH3 cells and total cytoplasmic RNA isolated 48 $\mathrm{hr}$ later; transcript mapping and densitometry were as in Fig. 4. Diagram shows the prolactin regulatory region from nucleotides -248 to +16 relative to the transcription start site; numbered boxes locate the three most promoter-proximal receptor binding sites; thick lines designate BamHI linker sequences.

unit (Fig. 7i,k). Similar results were obtained with the prolactin DNA fragments containing isolated receptor footprints $1,4,5$, or 6 (data not shown); footprints 2 and 7 have not been tested in this manner. Likewise, prolactin sequences were able to confer negative hormonal regulation upon the SV40 early, rabbit $\beta$-globin, and mouse metallothionein promoters (data not shown). In contrast, fusion of a GRE rendered the tk promoter strongly inducible by glucocorticoids (Fig. 7c,d,i), whereas the tk promoter alone specified a low level of transcription which is unaffected by hormone treatment (Fig. 7a,b).

Importantly, nGRE sequences, unlike the MTV46 sequence, dramatically increase expression of the tk promoter in the absence of glucocorticoids, and this stimulation is independent of the glucocorticoid receptor (Fig. 7). Thus, these results imply that the prolactin nGRE provides binding sites for at least two distinct components - a factor other than the glucocorticoid receptor that strongly enhances basal transcription efficiency, and the glucocorticoid receptor itself, which in the presence of hormone counteracts this constitutive enhancer activity.

\section{Discussion \\ Identification of negative glucocorticoid response elements}

We have employed several experimental approaches to identify regulatory elements associated with the bovine prolactin gene that are determinants of glucocorticoidmediated transcriptional repression. Glucocorticoid receptor footprinting, deletion, and linker substitution mutagenesis, as well as heterologous promoter fusions,
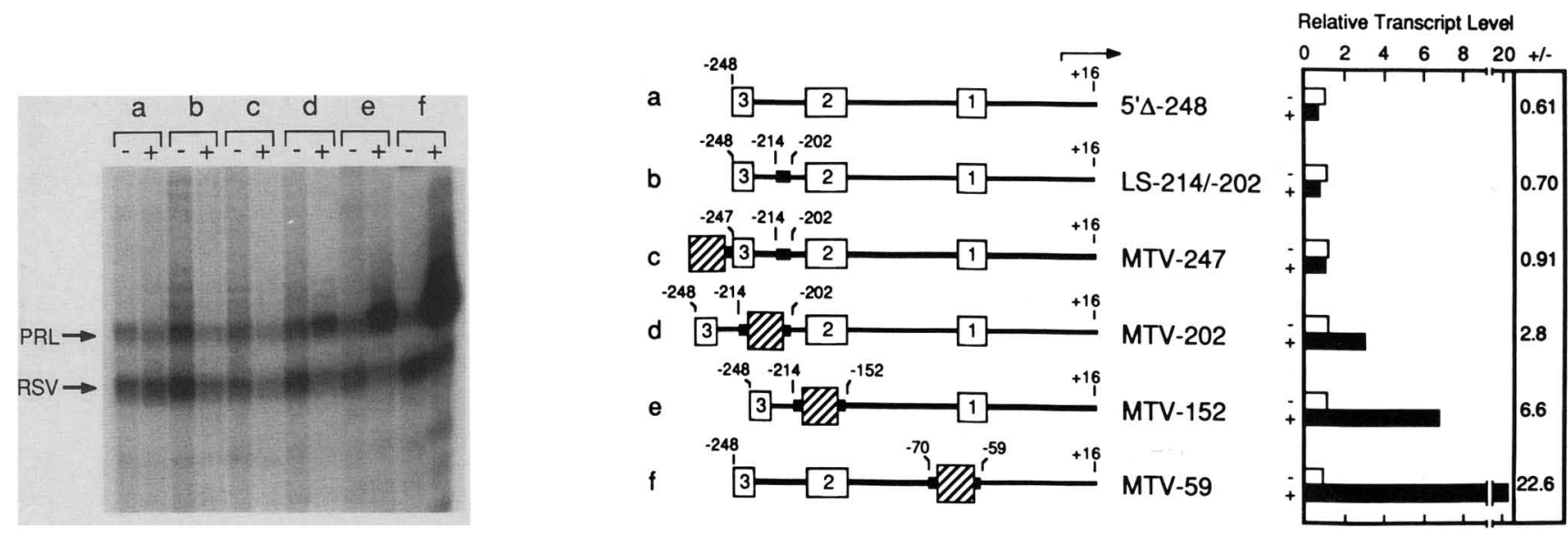

Figure 6. The prolactin promoter is glucocorticoid inducible when linked to an MTV GRE derivative. Test (prolactin-CAT fusions) and reference (pRSVcat) plasmids were cotransfected into GH3 cells and total cytoplasmic RNA isolated $48 \mathrm{hr}$ later. Transcript mapping and densitometry were as in Fig. 4. Diagram shows the prolactin regulatory region from -248 to +16 ; hatched boxes represent the MTV46 synthetic GRE fragment (see Materials and methods); thick lines designate BamHI linker sequences. 


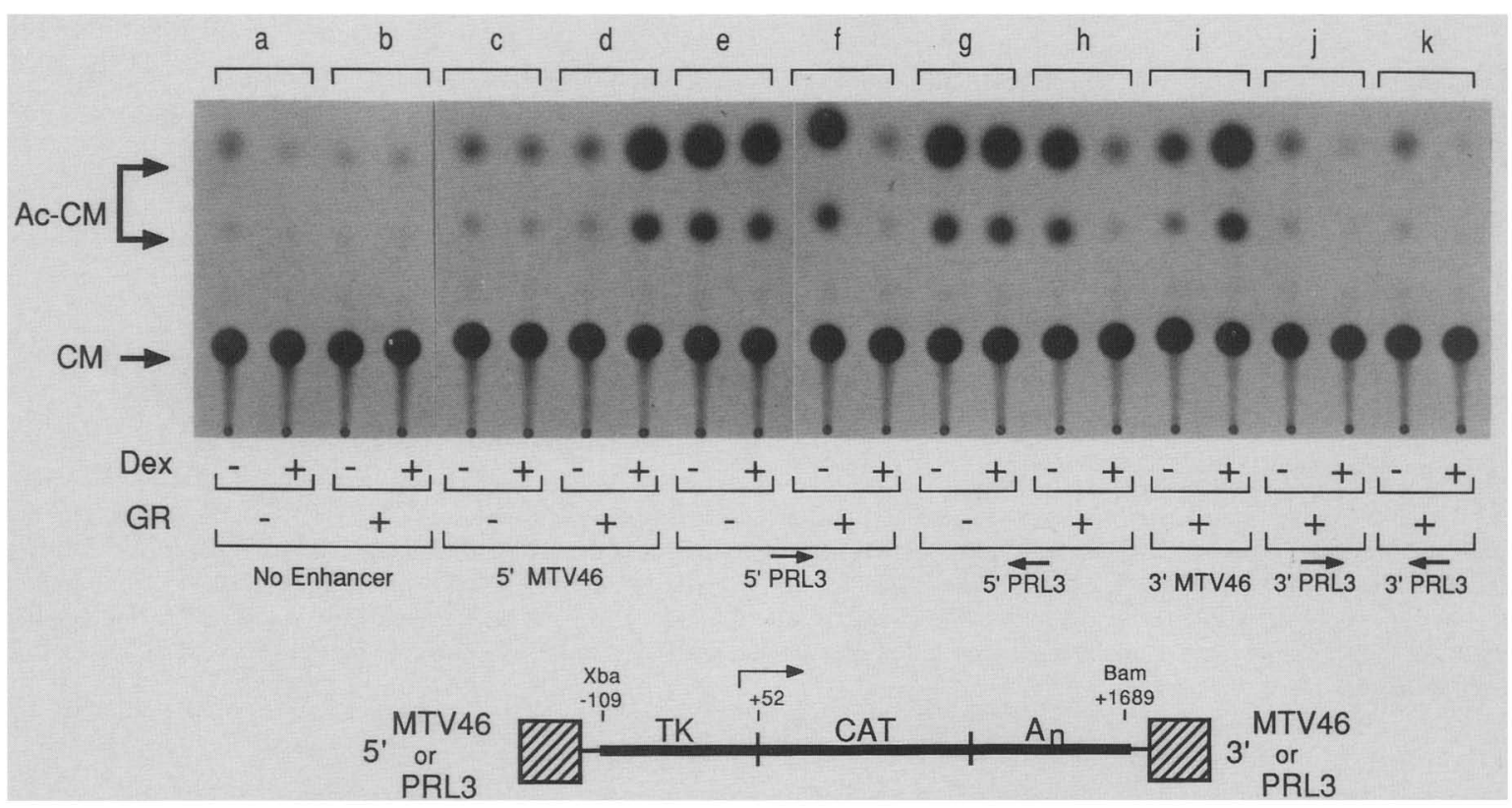

Figure 7. The prolactin nGRE modulates transcription from a linked tk promoter. nGREs function in an orientation-independent manner. Glucocorticoid receptor is not required for basal enhancement by nGRES. CV-1 cells were cotransfected with the tk-CAT fusion test plasmid indicated and either glucocorticoid receptor-expression plasmid pRSVGR (+GR) or a control plasmid lacking receptor sequences (-GR). The autoradiogram shows CAT assays from a representative transfection; similar results were obtained in $4\left(3^{\prime}\right.$ inserts) to 26 (5' inserts) repetitions. (Lanes $\left.a, b\right)$ Plasmid pOTCO, an enhancerless tk-CAT fusion; insertion of MTV46 at (lanes $c$,d) $\mathrm{XbaI}$ or (lane i) BamHI; insertion of PRL3 $(-247$ to -214$)$ at $X b a I$ in the (lanes $e, f)$ forward or (lanes $g, h)$ reverse orientation, or at $B a m H I$ in the (lane $i$ ) forward or (lane $k$ ) reverse orientation.

have identified a series of receptor-binding DNA sequences as functional components in the repression response. Demonstration of positive regulation of the prolactin promoter by an MTV-derived GRE, and of negative regulation conferred by the prolactin nGRE upon heterologous promoters in nonpituitary cells, indicate that the receptor binding sites themselves determine the nature of the hormonal regulation.

\section{Mechanism of receptor-mediated repression}

Our experiments demonstrate that the prolactin nGRE is able to function upon heterologous promoters at a distance, reminiscent of the behavior of other long-range operator elements (Gilmour et al. 1984; Brand et al. 1985; Gorman et al. 1985; Johnson and Herskowitz 1985; Goodbourn et al. 1986; Laimins et al. 1986; Larsen et al. 1986; Muglia and Rothman-Denses 1986; Nir et al. 1986; Siliciano and Tatchell 1986; Simpson et al. 1986; Hammer et al. 1987). The prolactin nGRE, however, is distinct from the operator elements described previously in that it appears to be a compound element that includes a constitutive enhancer-like component that activates transcription in the absence of glucocorticoids, together with a novel class of receptor binding sequences that negate the enhancement effect upon receptor binding.

We suggest that receptor binding at the prolactin nGRE results solely in the reversal of constitutive enhancer action, presumably by removing or otherwise neutralizing the actions of an enhancer-activating protein bound at an overlapping site; that is, it appears that the direct effect of receptor at the nGRE is to modulate enhancer activity rather than promoter activity. Consistent with this view, we have not observed repression of transcription to levels below that of the original basal promoter activity (Fig. 7 and data not shown). In addition, the constitutive enhancer activity associated with the prolactin nGRE is present both in pituitary and in some nonpituitary cells; however, in a cell line lacking that activity, the nGRE confers neither positive nor negative effects upon the linked promoter in the absence or presence of hormone (D. Sakai, unpubl.).

Adler et al. (1988) have reported that regions of the rat prolactin 5'-flanking region also confer glucocorticoid repressibility upon the tk promoter. In contrast to our results, however, the repression observed does not appear to correspond to a reversal of enhanced basal promoter activity. As the sequences of the rat and bovine genes differ considerably in the $5^{\prime}$-flanking region, and as Adler and colleagues did not characterize receptor binding sites, the explanation for the apparent distinction in regulatory mechanisms cannot readily be discerned.

Positive and negative regulation by the glucocorticoid receptor

The observation that a single transcriptional regulatory protein can effect both positive and negative control is 
not a novel one. The mechanisms that determine these distinct activities have been investigated in some detail for several prokaryotic regulators, such as the Escherichia coli cAMP receptor (Aiba 1983; Buc et al. 1987) and araC proteins (Martin et al. 1986; Lee et al. 1987), and the bacteriophage $\lambda c I$ protein (Ptashne 1986). In addition, results from a number of eukaryotic systems are consistent with the view that regulatory strategies may commonly employ combinations of positive and negative activities (e.g., see Goodbourn et al. 1986; Shore and Nasmyth 1987; Sudhof et al. 1987; Keleher et al. 1988). In the case of the glucocorticoid receptor, our data suggest that it effects its two modes of control as a single protein species that recognizes two distinct classes of DNA sequence elements.

Perhaps the simplest interpretation of our results is that the receptor assumes alternative conformations upon binding to GRE and nGRE sequences. One or both classes of DNA sequences recognized by the receptor might serve as an allosteric ligand, altering receptor structure such that binding to the nGRE, for example, would preclude positive regulatory activity. According to this scheme, receptor bound at the nGRE would compete or neutralize the constitutive enhancer factor bound nearby, but would itself have no direct effect on promoter function. Obviously, more complex models can also be envisioned; for example, different auxiliary factors might associate with receptors bound to GREs and nGREs, thereby conferring the distinct modes of hormonal regulation.

Miesfeld et al. (1987a,b) have shown that a small region of the glucocorticoid receptor that encompasses the DNA binding domain is necessary and sufficient for both positive and negative regulation. This implies that a single DNA-binding region within the receptor is able to recognize both GRE and nGRE sequences. A yeast regulatory protein, HAPl, also appears to bind specifically to two distinct DNA sequences, although it has not yet been determined whether it utilizes a common DNA binding domain (Pfeifer et al. 1987).

Further studies will be necessary to define in detail the specific nGRE nucleotides essential for receptor binding, for association of the putative constitutive enhancer factor, and perhaps for binding of additional factors. In any case, it seems likely from our experiments that distinct configurations of protein-DNA complexes will be involved in receptor-mediated positive and negative regulation. In particular, we suggest that the mere binding of receptor to sites near a promoter is insufficient to specify the nature of the regulatory response. Consistent with this view, distinct regions of the glucocorticoid receptor protein have recently been identified that are essential for negative and positive regulation (P. Godowski and K.R. Yamamoto, unpubl.).

\section{Materials and methods}

Plasmid constructions

Plasmids pRSVcat (Gorman et al. 1982), pPRLcat-1 and
pPRLcat-2 (Camper et al. 1985), pOTCO (DeFranco and Yamamoto 1986), and pRSVGR (Miesfeld et al. 1986) have been described previously.

Nested $5^{\prime}$ deletions of the bovine prolactin promoter were generated from pPRLcat- $1\left(5^{\prime} \Delta-983\right)$ by Bal31 or exonuclease III resection from the $N d e I$ site at $-1 \mathrm{~kb}$ or $B g I I I$ site at -248 . Following blunting of the DNA, plasmids were digested with $B g I I$ and the fragments bearing the deletions were isolated by electrophoresis in low-melt agarose. The fragments were ligated to the SmaI-BgII fragment of pUCl3 (Messing 1983), which regenerates the ampicillin resistance gene and fuses a polylinker to each deletion end point (Fig. 8). Deletions entering promoter sequences from the $3^{\prime}$ side were generated in a similar manner using pPRLcat-2 $\left(5^{\prime} \Delta-248\right)$ linearized at the HindIII site (Fig. 8). Deletion end points were determined by direct sequencing (Chen and Seeburg 1985) utilizing the M13 universal and reverse sequencing primers (Messing 1983); deletions are designated by the last wild-type nucleotide that is retained. Linker substitution mutants were derived by insertion of the small BamHI fragment from 5' deletions into the BamHI site of $3^{\prime}$ deletions (Fig. 8). The plasmid $(-214 /-247) 5^{\prime} \Delta-212$ was generated by the insertion of the small BamHI fragment from $5^{\prime}(\Delta)-212$ into the $B g I I I$ site of $3^{\prime} \Delta-214$.

For construction of tk promoter derivatives, prolactin promoter fragments were excised using existing restriction sites and sites within the polylinker of deletion derivatives, and subcloned into the $\mathrm{XbaI}$ or BamHI site of pOTCO (see Fig. 7). In some cases, fragments were initially subcloned into pUCI2B / a derivative of pUC12 with an inverted duplication of the polylinker region; D. Sakai, unpubl.) to customize flanking linker sequences prior to insertion into the reporter plasmid. MTV46, a self-complementary synthetic 46-bp GRE generously provided by $\mathrm{P}$. Searle and R. Palmiter (University of Washington, Seattle), contains an inverted duplication of MTV nucleotides -123 to -105: (5'-GATCCAAATGTTCTGATCTGAGCCATGGCTCAGATCAGAACATTTG-3'); it was similarly introduced into pOTCO and also into the BamHI or BgIII site of linker substitution mutants to generate the plasmids depicted in Figure 6.

All plasmids were propagated in E. coli DH5 (Hanahan 1983) and purified by alkaline lysis (Birnboim and Doly 1979) followed by two or three successive bandings in CsCl-ethidium bromide gradients. The concentrations and purity of all plasmids were verified by UV absorption and agarose gel electrophoresis.

\section{Cell culture and transfections}

GH3 rat pituitary tumor cells (Tashjian 1979) were propagated in a $1: 1$ mixture of Dulbecco's modified Eagle medium and Ham's F-12 medium supplemented with $10 \%$ fetal bovine serum. Approximately $10^{7}$ cells were plated in $15-\mathrm{cm}$ dishes 48 hr prior to transfection (Camper et al. 1985). Monolayers were rinsed gently with phosphate-buffered saline (PBS) three times and overlaid with $15 \mathrm{ml}$ of Ham's F- 12 containing $50 \mathrm{~mm}$ Tris$\mathrm{HCl}(\mathrm{pH} 7.5), 100 \mu \mathrm{g} / \mathrm{ml}$ of DEAE-dextran (Sompayrac and Danna 1981), $1 \mu \mathrm{g}$ of pRSVcat, and $15 \mu \mathrm{g}$ of test plasmid and incubated $1 \mathrm{hr}$ at $37^{\circ} \mathrm{C}$. The cells were then rinsed once with PBS, replenished with growth medium containing $100 \mathrm{U} / \mathrm{ml}$ penicillin, $0.1 \mathrm{mg} / \mathrm{ml}$ streptomycin, and 0 or $0.1 \mu \mathrm{M}$ dexamethasone, and incubated for an additional $48 \mathrm{hr}$.

CV-1 monkey kidney cells were propagated in Dulbecco's modified Eagle medium containing $5 \%$ fetal bovine serum. Transient cotransfections were done essentially as previously described (Miesfeld et al. 1986). In brief, freshly fed cultures $\left(10^{6}\right.$ cells per $10-\mathrm{cm}$ dish/ were overlaid with $1 \mathrm{ml}$ of calcium phos- 

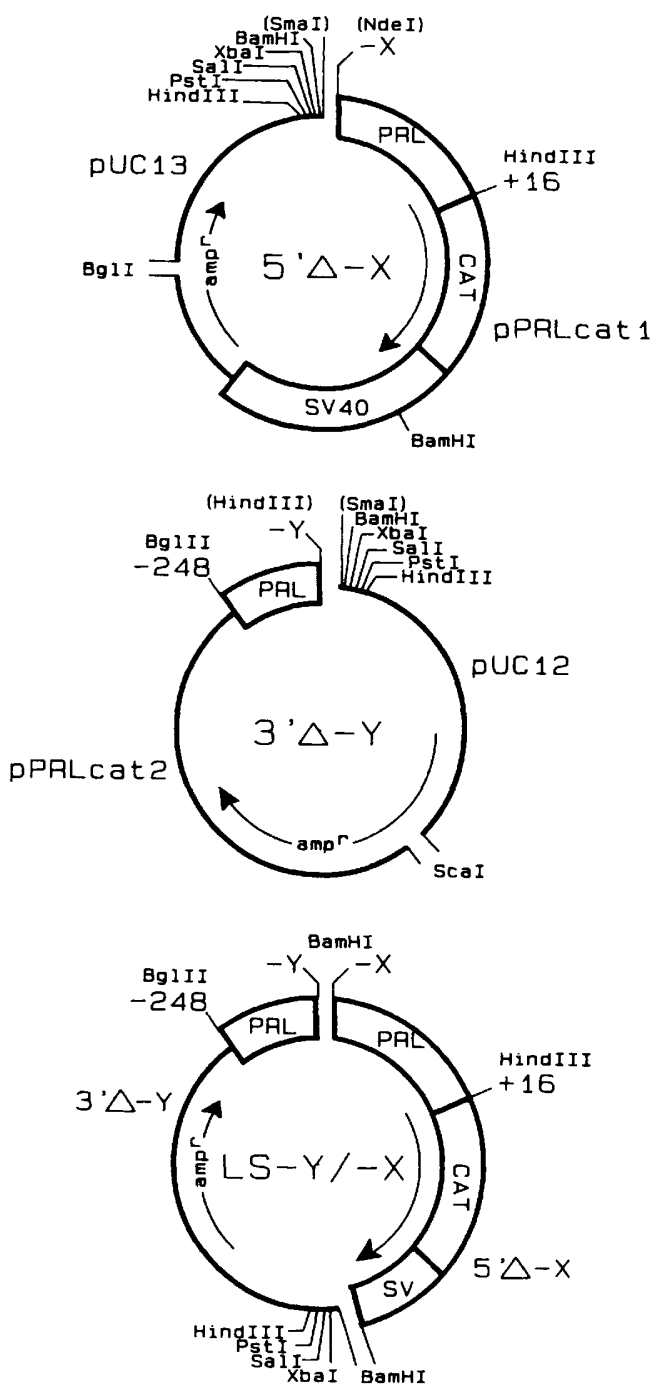

Figure 8. Construction of the bovine prolactin terminal and linker substitution mutants. See Materials and methods for details.

phate-DNA precipitate containing $5 \mu \mathrm{g}$ of pRSVGR and $1 \mu \mathrm{g}$ of test plasmid. Chloroquine was added to $0.1 \mathrm{mM}$ (Luthman and Magnusson 1983) and the cells incubated $5 \mathrm{hr}$ at $37^{\circ} \mathrm{C}$. The monolayers were rinsed once with PBS, replenished with growth medium with or without $0.1 \mu \mathrm{M}$ dexamethasone, and incubated an additional $24 \mathrm{hr}$. Extracts were prepared and CAT assays were performed as described previously (Gorman et al. 1982; Camper et al. 1985).

\section{Isolation and analysis of RNA}

Monolayer cultures were rinsed twice with Tris-buffered saline and then lysed in $4 \mathrm{ml}$ of $10 \mathrm{mM}$ Tris- $\mathrm{HCl}(\mathrm{pH} 7.5), 10 \mathrm{~mm}$ $\mathrm{NaCl}, 1 \% \mathrm{NP}-40$ and $10 \mathrm{~mm}$ vanadyl ribonucleosides (Berger and Birkenmeier 1979). After $10 \mathrm{~min}$ at room temperature, the lysate was transferred to centrifuge tubes and extracted twice with equal volumes of buffered phenol/chloroform/isoamyl alcohol $\{25: 24: 1\}$, once with chloroform/isoamyl alcohol $(24: 1)$, and ethanol precipitated. Poly(A) ${ }^{+}$RNA was prepared by oligo(dT)-cellulose chromatography (Aviv and Leder 1972).

Transcript mapping was performed essentially as described by Melton et al. (1984) except that nuclease digestion was performed at room temperature for $1 \mathrm{hr}$ with RNase $A$ and $T_{1}$ at concentrations of $4-10 \mu \mathrm{g} / \mathrm{ml}$ and $40 \mathrm{U} / \mathrm{ml}$, respectively. In the hybridizations, probe was present at 100 -fold excess over CAT transcripts as determined by titration. Antisense RNA probes (sp. act. $=5 \times 10^{8} \mathrm{dpm} / \mu \mathrm{g}$ ) were transcribed from the 466-bp PstI-RsaI fragment of pPRLcat-1 (which spans the prolactin start site, see Fig. 4), cloned into pSP65 (Melton et al. 1984; Camper et al. 1985), and purified on sequencing gels.

\section{DNase I footprinting}

Purified rat liver glucocorticoid receptor was prepared according to Wrange et al. (1986). Probes were prepared from plasmid pPRLbgh-1 (D. Sakai, unpubl.) and from plasmid with MTV-152 (Fig. 6). DNAs were 5'-end-labeled or 3'-end-labeled polynucleotide kinase or DNA polymerase I (Klenow fragment). They were subjected to secondary digestion with restriction enzymes that yielded 650 - to 1000 -bp probe fragments that were then purified from low-melt agarose gels by the glass bead method (Vogelstein and Gillespie 1979).

DNA binding reactions (Payvar et al. 1983) included 2-5 fmoles of ${ }^{32} \mathrm{P}$ end-labeled DNA fragment in 100-250 $\mu \mathrm{l}$ of binding buffer ( $20 \mathrm{mM}$ Tris- $\mathrm{HCl}$, (pH 7.5), $1 \mathrm{~mm}$ EDTA, $2 \mathrm{~mm}$ $\mathrm{MgCl}_{2}, 50 \mathrm{mM} \mathrm{NaCl}, 20 \mathrm{mM}$ dithiothreitol, $100 \mu \mathrm{g} / \mathrm{ml}$ of insulin, $20 \%$ glycerol, $1 \mu \mathrm{M}$ dexamethasone) and 20-400 ng of receptor. Competitor DNA was mixed with the probe DNA prior to receptor addition. Binding was for $15 \mathrm{~min}$ at room temperature. DNase I (3-60 ng/ml depending upon receptor concentration) was then added along with $1 \mathrm{~mm} \mathrm{CaCl}, 1 \mathrm{~mm}$ $\mathrm{MgCl}_{2}$, and $0.1 \mu \mathrm{g} / \mathrm{ml} \mathrm{pBR332}$ DNA; incubation was for $1 \mathrm{~min}$ at room temperature. The reaction mixture was adjusted to 10 mM of $\mathrm{Na}_{2}$ EDTA, $0.1 \%$ SDS, and $200 \mu \mathrm{g} / \mathrm{ml}$ proteinase $\mathrm{K}$ and incubated for $30 \mathrm{~min}$ at $37^{\circ} \mathrm{C}$. The nucleic acids were extracted with buffered phenol/chloroform $(1: 1)$, ethanol-precipitated, and electrophoresed on $6 \%$ sequencing gels along with sequencing ladders.

\section{Acknowledgments}

We thank Sandy Johnson, Josh LaBaer, and Rudi Grosschedl for helpful comments on the manuscript, Chuck Bevan for preparation of the typescript, and Bonnie Maler for help with the figures. This work was supported by grants from the National Institutes of Health and the Swedish Medical Research Council; postdoctoral fellowship support to D.D.S. and S.H. was from the NIH.

\section{References}

Adler, S., M.L. Waterman, X. He, and M.G. Rosenfeld. 1988. Steroid receptor-mediated inhibition of rat prolactin gene expression does not require the receptor DNA-binding domain. Cell 52: 685-695.

Aiba, H. 1983. Autoregulation of the Escherichia coli crp gene: CRP is a transcriptional repressor for its own gene. Cell 32: $141-149$.

Aviv, H. and P. Leder. 1972. Purification of biologically active globin messenger RNA by chromatography on oligothymidylic acid-cellulose. Proc. Natl. Acad. Sci. 69: 1408-1412.

Berger, S.L. and C.S. Birkenmeier. 1979. Inhibition of intractable nucleases with ribonucleoside-vanadyl complexes: isolation of messenger ribonucleic acid from resting lymphocytes. Biochemistry 18: 5143-5149.

Birnboim, H.C. and J. Doly. 1979. A rapid alkaline extraction procedure for screening recombinant plasmid DNA. Nucleic Acids Res. 7: 1513-1523. 
Borrelli, E., R. Hen, C. Wasylyk, B. Wasylyk, and P. Chambon. 1986. The immunoglobulin heavy chain enhancer is stimulated by the adenovirus type 2 ElA products in mouse fibroblasts. Proc. Natl. Acad. Sci. 83: 2846-2849.

Bram, R.J., N.F. Lue, and R.D. Kornberg. 1986. A GAL family of upstream activating sequences in yeast: roles in both induction and repression of transcription. EMBO J. 5: 603-608.

Brand, A.H., L. Breeden, J. Abraham, R. Sternglanz, and K. Nasmyth. 1985. Characterization of a 'silencer' in yeast: A DNA sequence with properties opposite to those of a transcriptional enhancer. Cell 41: 41-48.

Buc, H., M. Amouyal, M. Buvckle, M. Herbert, A. Kolb, D. Kotlarz, M. Menendez, S. Rimsky, A. Spassky, and E. Yeramian. 1987. Activation of transcription by the cyclic AMP receptor protein. In RNA polymerase and regulation of transcription, 16th Steenbock Symposium. (ed. W.S. Reznikoff, et al.), pp 115-125. Elsevier Science Publishing, New York.

Buetti, E. and B. Kühnel. 1986. Distinct sequence elements involved in the glucocorticoid regulation of the mouse mammary tumor virus promoter identified by linker scanning mutagenesis. J. Mol. Biol. 190: 379-389.

Camper, S.A., D.N. Luck, Y. Yao, R.P. Woychik, R.G. Goodwin R.H. Lyons, Jr., and F.M. Rottman. 1984. Characterization of the bovine prolactin gene. DNA 3: 237-249.

Camper, S.A., Y.A.S. Yao, and F.M. Rottman. 1985. Hormonal regulation of the bovine prolactin promoter in rat pituitary tumor cells. J. Biol. Chem. 260: 12246-12251.

Chandler, V.L., B.A. Maler, and K.R. Yamamoto. 1983. DNA sequences bound specifically by glucocorticoid receptor in vitro render a heterologous promoter hormone responsive in vivo. Cell 33: 489-499.

Charron, J. and J. Drouin. 1986. Glucocorticoid inhibition of transcription from episomal proopiomelanocortin gene promoter. Proc. Natl. Acad. Sci. 83: 8903-8907.

Chen, E.Y. and P.H. Seeburg. 1985. Supercoil sequencing: A fast and simple method for sequencing plasmid DNA. DNA 4: $165-170$

Danesch, U., B. Gloss, W. Schmid, G. Schutz, R. Schule, and R. Renkawitz. 1987. Glucocorticoid induction of the rat tryptophan oxygenase gene is mediated by two widely separated glucocorticoid-responsive elements. EMBO J. 6: 625-630.

DeFranco, D. and K.R. Yamamoto. 1986. Two different factors act separately or together to specify functionally distinct activities at a single transcription enhancer. Mol. Cell. Biol. 6: $993-1001$.

DeFranco, D., O. Wrange, J. Merryweather, and K.R. Yamamoto. 1985. Biological activity of a glucocorticoid regulated enhancer: DNA sequence requirements and interactions with other transcriptional enhancers. In Genome rearrangement, UCLA Symposia on Molecular and Cellular Biology, New Series (ed. I. Hershkowitz and M. Simon), vol. 20, pp. 305-321. Alan R. Liss, Inc., New York.

Fremeau, Jr., R.T., J.R. Lundblad, D.B. Pritchett, J.N. Wilcox, and J.L. Roberts. 1986. Regulation of pro-opiomelanocortin gene transcription in individual cell nuclei. Science 234: $1265-1269$.

Frisch, S.M. and H.E. Ruley. 1987. Transcription from the stromelysin promoter is induced by interleukin-1 and repressed by dexamethasone. J. Biol. Chem. 262: 16300-16304.

Gilmour, R.S., D.A. Spandidos, J.K. Vass, J.W. Gow and J. Paul. 1984. A negative regulatory sequence near the mouse $\beta$-maj globin gene associated with a region of potential Z-DNA. EMBO I. 3: 1263-1272.

Goodbourn, S., H. Burstein, and T. Maniatis. 1986. The human $\beta$-interferon gene enhancer is under negative control. Cell 45: $601-610$.
Gorman, C.M., G.T. Merlino, M.C. Willingham, I. Pastan, and B.H. Howard. 1982. The Rous sarcoma virus long terminal repeat is a strong promoter when introduced into a variety of eukaryotic cells by DNA-mediated transfection. Proc. Natl. Acad. Sci. 79: 6777-6781.

Gorman, C.M., P.W.J. Rigby, and D.P. Lane. 1985. Negative regulation of viral enhancers in undifferentiated embryonic stem cells. Cell 42: 519-526.

Hammer, R.E., R. Krumlauf, S.A. Camper, R.L. Brinster, and S.M. Tilghman. 1987. Diversity of alpha-fetoprotein gene expression in mice is generated by a combination of separate enhancer elements. Science 235: 53-58.

Hanahan, D. 1983. Studies on transformation of Escherichia coli with plasmids. $J$. Mol. Biol. 166:557-580.

Israel, A. and S.N. Cohen. 1985. Hormonally mediated negative regulation of human pro-opiomelanocortin gene expression after transfection into mouse L cells. Mol. Cell. Biol. 5: 2443-2453.

Jantzen, H.-M., U. Strähle, B. Gloss, F. Stewart, W. Schmid, M. Boshart, R. Miksicek and G. Schutz. 1987. Cooperativity of glucocorticoid response elements located far upstream of the tyrosine aminotransferase gene. Cell 49: 29-38.

Johnson, A.D. and I. Herskowitz. 1985. A repressor (MATa2 product) and its operator control expression of a set of celltype specific genes in yeast. Cell 42: 237-247.

Johnston, S.A., M.J. Zavortink, C. Debouck, and J.E. Hopper. 1986. Functional domains of the yeast regulatory protein GAL4. Proc. Natl. Acad. Sci. 83: 6553-6557.

Karin, M., A. Haslinger, H. Holtgreve, R.I. Richards, P. Krauter, H.M. Westphal, and M. Beato. 1984. Characterization of DNA sequences through which cadmium and glucocorticoid hormones induce human metallothionein- $\mathrm{II}_{\mathrm{a}}$ gene. $\mathrm{Na}$ ture 308: 513-519.

Keleher, C.A., C. Goutte, and A.D. Johnson. 1988. The yeast cell-type specific repressor $\alpha 2$ acts cooperatively with a noncell-type-specific protein. Cell 53: 927-936.

Laimins, L., M. Holmgren-König, and G. Khoury. 1986. Transcriptional 'silencer' element in rat repetitive sequences associated with the rat insulin 1 gene locus. Proc. Natl. Acad. Sci. 83: 3151-3155.

Larsen, P.R., J.W. Harney, and D.D. Moore. 1986. Repression mediates cell-type-specific expression of the rat growth hormone gene. Proc. Natl. Acad. Sci. 83: 8283-8287.

Lee, N., C. Francklyn, and E.P. Hamilton. 1987. Arabinose-induced binding of $\mathrm{AraC}$ protein to aral $_{2}$ activates the araBAD operon promoter. Proc. Natl. Acad. Sci. 84: 8814-8818.

Luthman, H. and G. Magnusson. 1983. High-efficiency polyoma DNA transfection of chloroquine-treated cells. Nucleic Acids Res. 11: 1295-1308.

Martin, K., L. Huo, and R.F. Schleif. 1986. The DNA loop model for ara repression: araC protein occupies the proposed loop sites in vivo and repression-negative mutations lie in these same sites. Proc. Natl. Acad. Sci. 83: 36543658 .

Melton, D.A., P.A. Krieg, M.R. Rebagliati, T. Maniatis, K. Zinn, and M.R. Green. 1984. Efficient in vitro synthesis of biologically active RNA and RNA hybridization probes from plasmids containing a bacteriophage SP6 promoter. Nucleic Acids Res. 12: 7035-7056.

Messing, J. 1983. New M13 vectors for cloning. Methods Enzymol. 101: 20-78.

Miesfeld, R., S. Okret, A.-C. Wikstrom, Ö. Wrange, J.- $\AA$. Gustafsson, and K.R. Yamamoto. 1984. Characterization of a steroid hormone receptor gene and mRNA in wild-type and mutant cells. Nature 312: 779-781.

Miesfeld, R., S. Rusconi, P.J. Godowski, B.A. Maler, S. Okret, 
A.-C. Wikstrom, J.-^̊. Gustafsson, and K.R. Yamamoto. 1986. Genetic complementation of a glucocorticoid receptor deficiency by expression of cloned receptor cDNA. Cell 46: 389-399.

Miesfeld, R., P.J. Godowski, B.A. Maler, and K.R. Yamamoto. 1987a. Glucocorticoid receptor mutants that define a small region sufficient for enhancer activation. Science 236: 423427.

Miesfeld, R., D. Sakai, A. Inoue, M. Schena, P.J. Godowski, and K.R. Yamamoto. 1987b. Glucocorticoid receptor sequences that confer positive and negative transcriptional regulation. In Steroid hormone action, UCLA Symposium on Molecular and Cellular Biology (ed. G. Ringold). Alan R. Liss, Inc., New York. (In press)

Miksicek, R., A. Heber, W. Schmid, U. Danesch, B. Posseckert, M. Beato, and G. Schutz. 1986. Glucocorticoid responsiveness of the transcriptional enhancer of Moloney murine sarcoma virus. Cell 46: 283-290.

Moore, D.D., A.R. Marks, D.I. Buckley, G. Kapler, F. Payvar, and H.M. Goodman. 1985. The first intron of the human growth hormone gene contains a binding site for glucocorticoid receptor. Proc. Natl. Acad. Sci. 82: 699-702.

Muglia, L. and L.B. Rothman-Denes. 1986. Cell-type-specific negative regulatory element in the control region of the rat $\alpha$-fetoprotein gene. Pro. Natl. Acad. Sci. 83: 7653-7657.

Nir, U., M.D. Walker, and W.J. Rutter. 1986. Regulation of rat insulin 1 gene expression: Evidence for negative regulation in nonpancreatic cells. Proc. Natl. Acad. Sci. 83: 31803184.

Payvar, F., D. DeFranco, G.L. Firestone, B. Edgar, Ö. Wrange, S Okret, J.-A. Gustafsson, and K.R. Yamamoto. 1983. Sequence-specific binding of glucocorticoid receptor to MTV DNA at sites within and upstream of the transcribed region. Cell 35: 381-392.

Pfeifer, K., T. Prezant, and L. Guarente. 1987. Yeast HAP1 activator binds to two upstream activation sites of different sequence. Cell 49: 19-27.

Picard, D. and K.R. Yamamoto. 1987. Two signals mediate hormone-dependent nuclear localization of the glucocorticoid receptor. $E M B O$ /. 6: 3333-3340.

Ponta, H., N. Kennedy, P. Skroch, N. E. Hynes, and B. Groner. 1985. Hormonal response region in the mouse mammary tumor virus long terminal repeat can be dissociated from the proviral promoter and has enhancer properties. Proc. Natl. Acad. Sci. 82: 1020-1024.

Ptashne, M. 1986. A genetic switch: Gene control and phage $\lambda$. Cell Cell Press, Cambridge, MA and Blackwell, Palo Alto, California.

Renkawitz, R., G. Schutz, D. von der Ahe, and M. Beato. 1984. Sequences in the promoter region of the chicken lysozyme gene required for steroid regulation and receptor binding. Cell 37: 503-510.

Rottman, F., S. Camper, E. Goodwin, R. Hampson, R. Lyons, D. Sakai, R. Woychik, and Y. Yao. 1986. Structure and regulated expression of bovine prolactin and bovine growth hormone genes. In Molecular and cellular aspects of reproduction (ed. D.S. Dhindsa and O.P. Bahl), pp. 281-299. Plenum Press, New York.

Scheidereit, C., S. Geisse, H.M. Westphal, and M. Beato. 1983. The glucocorticoid receptor binds to defined nucleotide sequences near the promoter of mouse mammary tumor virus. Nature 304: 749-752.

Shore, D. and K. Nasmyth. 1987. Purification and cloning of a DNA binding protein from yeast that binds to both silencer and activation elements. Cell 51: 721-732.

Siliciano, P.G. and K. Tatchell. 1986. Identification of the DNA

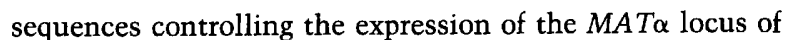
yeast. Proc. Natl. Acad. Sci. 83: 2320-2324.

Simpson, J., J. Schell, M. Van Montagu, and L. Herrera-Estrella. 1986. Light-inducible and tissue-specific pea lhcp gene expression involves an upstream element combining enhancer- and silencer-like properties. Nature 323: 551-554.

Sompayrac, L.M. and K.J. Danna. 1981. Efficient infection of monkey cells with DNA of simian virus 40 . Proc. Natl. Acad. Sci. 78: 7575-7578.

Sudhof, T.C., D.W. Russell, M.S. Brown, and J.L. Goldstein. 1987. 42 bp element from LDL receptor gene confers endproduct repression by sterols when inserted into viral TK promoter. Cell 48: 1061-1069.

Tashjian, Ir., A.H. 1979. Clonal strains of hormone-producing pituitary cells. Methods Enzymol. 58: 527-535.

Vogelstein, B. and D. Gillespie. 1979. Preparative and analytical purification of DNA fragments from agarose. Proc. Natl. Acad. Sci. 76: 615-619.

Weiner, F.R., M.J. Czaja, D.M. Jefferson, M.-A. Giambrone, R. Tur-Kaspa, L.M. Reid, and M.A. Zern. 1987. The effects of dexamethasone on in vitro collagen gene expression. J. Biol. Chem. 262: 6955-6958.

Wrange, Ö., J. Carlstedt-Duke, and J.-Å. Gustafsson. 1986. Stoichiometric analysis of the specific interaction of the glucocorticoid receptor with DNA. I. Biol. Chem. 261: 1177011778 .

Yamamoto, K.R. 1985. Steroid receptor regulated transcription of specific genes and gene networks. Annu. Rev. Genet. 19: $209-252$. 


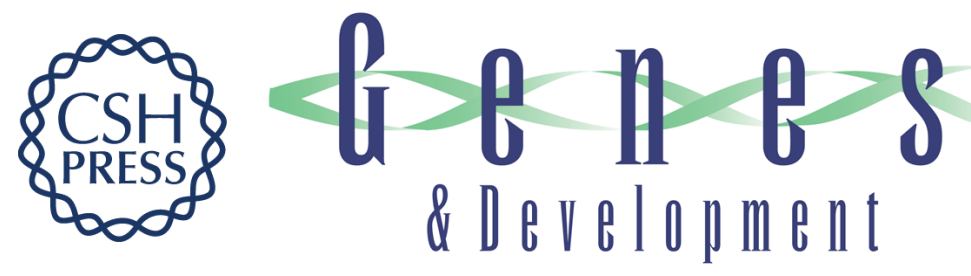

\section{Hormone-mediated repression: a negative glucocorticoid response element from the bovine prolactin gene.}

D D Sakai, S Helms, J Carlstedt-Duke, et al.

Genes Dev. 1988, 2:

Access the most recent version at doi:10.1101/gad.2.9.1144

References This article cites 60 articles, 25 of which can be accessed free at: http://genesdev.cshlp.org/content/2/9/1144.full.html\#ref-list-1

License

Email Alerting

Service

Receive free email alerts when new articles cite this article - sign up in the box at the top right corner of the article or click here.

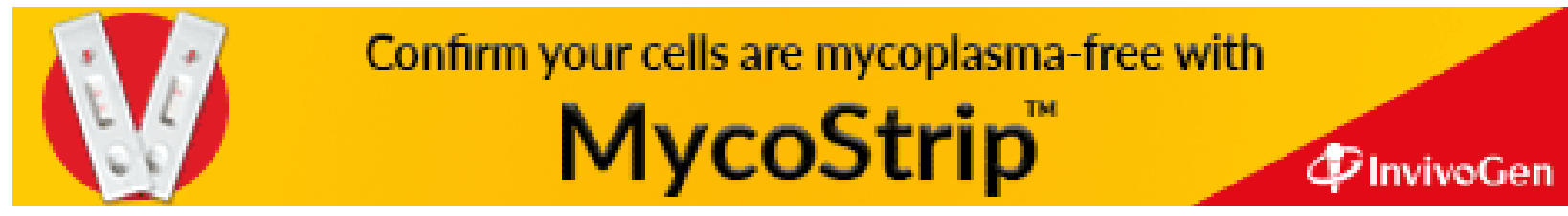

